\title{
sciendo
}

Current Issues in Pharmacy and Medical Sciences

Formerly ANNALES UNIVERSITATIS MARIAE CURIE-SKLODOWSKA, SECTIO DDD, PHARMACIA

journal homepage: http://www.curipms.umlub.pl/

\section{Evaluation of apical root resorption occurrence in orthodontic patients treated with fixed braces depending on selected clinical parameters}

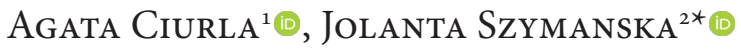 \\ ${ }^{1}$ Dentist' Office Orto-Punkt, Mościckiego Street 72/1, Tarnów, Poland \\ 2 Department of Integrated Pediatric Dentistry, Chair of Integrated Dentistry, Medical University of Lublin, Poland
}

\section{ARTICLE INFO \\ Received 18 September 2020 Accepted 10 January 2021}

\section{Keywords:}

orthodontics,

external apical resorption

(EARR),

fixed orthodontic appliances.

\begin{abstract}
An aim of the work was analysis of the possible connections between the selected clinical parameters and external apical root resorption (EARR) in patients after orthodontic treatment.

The study comprised 101 persons, who underwent complex orthodontic treatment with the use of fixed braces (straight-arch technique).

The teeth chosen for measurement of resorption level were central and lateral incisors of mandible and maxilla, as well as maxillary first molars, which are the most susceptible to root resorption. The roots were measured on the basis of the dental radiographs taken before and at the end of treatment. The measurements were made on digital radiographs with the use of diagnostic software (Planmeca Romexis ${ }^{\bullet}$ Viewer), which allows the image filters ensure the highest precision when localizing roots end points. Proportional measurements of the chosen teeth were made with the use of Linge's method and Linge's method modified by Brezniak et al. For further analysis, the persons taking part in the study were divided into two groups depending on the presence of postorthodontic EARR or its lack, resulting from radiographic measurements: a control group comprising 61 patients without EARR (with $0.90 \leq \mathrm{rRCR} \leq 1.00$ ) and a study group including 40 patients with EARR ( $\mathrm{rRCR}<0.90)$. In statistical analysis there was used verification of statistical hypotheses based on the following tests: Pearson's chi-squared test, Student's t-test, Mann-Whitney U test.

On the basis of the made analyses and achieved results, it was found out that age, sex, type of skeletal malocclusion, increased overjet and overbite do not constitute risk factors for EARR occurrence. Excessive proclination of central and lateral incisors of mandible and maxilla predisposes to shortening the roots of these teeth during orthodontic treatment with fixed braces $(\mathrm{p}<0.01)$.
\end{abstract}

\section{INTRODUCTION}

Root resorption constitutes one of the most serious complications connected with orthodontic treatment [1,2]. When giving consent for undergoing the treatment, patients are informed about possible complications which can occur during or after the end of treatment. Dynamic development in the field of orthodontics bears new opportunities, such as, more aesthetic braces, shorter time of treatment, limited necessity of cooperation with patient and almost a guarantee of therapeutic success. Achievement of aesthetic result and

\footnotetext{
* Corresponding author

e-mail: jolanta.szymanska@umlub.pl
}

correct occlusive conditions does not equate with therapeutic success. A vital part of treatment outcomes evaluation is an analysis of panoramic photos taken before the beginning and after the end of treatment, or just before an active therapeutic phase is finished $[3,4]$. The roots should not touch each other, the long axes of teeth should be parallel, and the shape of the roots should not differ from that before the treatment. Change of roots shape means occurrence of resorption process $[3,4]$. In some cases, significant shortening of roots length is observed. When resorption occurs, despite ideal occlusal relationships and patient's satisfaction with a beautiful smile, therapeutic success remains doubtful. 
Root resorption as a side effect of orthodontic treatment has been known for almost a hundred years [5]. In deciduous dentition it is a physiologic process. As an undesirable process in permanent teeth it even occurs in persons not undergoing orthodontic treatment (7-13\%), however it much more frequently appears in the roots of teeth subjected to orthodontic treatment $[6,7]$. In persons affected by resorption, who did not wear braces, external apical root resorption (EARR) is probably the result of occlusive forces [6,7].

Initially Brezniak and Wasserstein suggested a division of factors causing pathological resorption into biological, mechanical, combined biological-mechanical and others [8]. Mechanical factors initiate the process of root resorption as a result of local inhibition of blood flow under the influence of pressure. Biological factors are responsible for development of resorption, they influence its course, and control physiologic and morphologic periodontal changes $[9,10]$. Nowadays as causes of resorption, other authors distinguished patient-related factors and treatment-related ones [11]. The patient-related factors include: genetic predisposition, age, tooth-root morphology, bone thickness. The treatment-related factors, among others, include: the magnitude, type (continuous or intermittent), direction and duration of the applied orthodontic force, nature of tooth movement (intrusion, extrusion, tipping or bodily movement), type of malocclusion, appliance type, archwire sequence [9,11].

An aim of the work was an analysis of selected connections between an occurrence of external root resorption of central and lateral incisors of mandible and maxilla, as well as maxillary first molars, and selected patient-related and treatment-related factors in patients treated with fixed appliance.

\section{MATERIALS AND METHODS}

The study included 101 persons. An average patients' age was 22 years $/ 9$ months ( \pm 6 years $/ 3$ months), while an average duration of treatment was 31.1 months ( \pm 6 months). All the patients underwent complex orthodontic treatment with the use of fixed braces (straight-arch technique). The study participants were supposed to fulfill the following criteria: complete anamnestic and clinical data; clear, possible to evaluate X-ray radiographs (orthopantomograms) taken before and after the treatment with the use of the same equipment; studied teeth free from breaks, wears or incisal caries between the measurements. Patients with teeth injuries, unfinished root development, with previous endodontic treatment in selected teeth, and with previous orthodontic treatment with fixed braces, were not included into the study. Moreover, persons with systemic disease influencing teeth hard tissues were also excluded from the study. All the patients were treated by the same doctor.

The teeth chosen for measurement of resorption level were central and lateral incisors of mandible and maxilla, as well as maxillary first molars $[12,13]$. The roots were measured on the basis of the dental radiographs taken before and at the end of treatment, as in the previous studies [14-18]. The measurements were made on digital radiographs with the use of diagnostic software (Planmeca Romexis ${ }^{\circledR}$ Viewer), which allowed the image filters ensure the highest precision when localizing roots end points. All the pictures were previously calibrated. Proportional measurements of chosen teeth were made with the use of Linge's and Linge's method (1991) and Linge's method modified by Brezniak et al. (2004) [19,20]. Ratio of crowns length before and after the procedure $(\mathrm{C} 1 / \mathrm{C} 2)$ was used as a strengthening factor $(\mathrm{C} 1 / \mathrm{C} 2)$, as it is assumed that during an orthodontic treatment the crown's length does not change. When, during the procedure, the root became shorter, root resporption level was calculated on the basis of the equation $\mathrm{R} 1$ - R2 (C1/C2). For further analysis, the persons taking part in the study were divided into two groups depending on the presence of postorthodontic EARR or its lack, resulting from radiographic measurements: a control group comprising 61 patients without EARR (with $0.90 \leq \mathrm{rRCR} \leq 1.00$ ) and a study group including 40 patients with EARR (rRCR $<0.90)$.

Measurement reproducibility was statistically evaluated, comparing double measurements from the X-ray photographs of ten randomly chosen patients. The period between the measurements was equal to 3 weeks. The measurement error was calculated on the basis of the Dahlberg's formula,

$$
\mathrm{S}=\sqrt{\Sigma \mathrm{d} 2 / 2 \mathrm{n}}
$$

where $\mathrm{d}$ is a difference between the repeated measurements, while $\mathrm{n}$ is a number of repeated measurements with pairs [21].

The consent of the Bioethical Committee at the Medical University of Lublin (KE-0254/335/2018) was obtained for conduction of the studies. Before the beginning of the study, written consent was collected from all the participants, in accordance with the Helsinki Declaration (version 2008, https://www.wma.net/what-we-do/medical-ethics/ declaration-of-helsinki/doh-oct2008/).

The selected clinical and therapeutic variables were analysed: sex, age, type of skeletal malocclusion, proclination angle of maxillary and mandibular incisors, overjet, overbite. In order to classify patient's skeleton, lateral cephalometric radiographs were measured, taken before the treatment. In cephalometric photograph, proclination angle of upper incisors was evaluated choosing outline of the most proclined tooth from the group of all upper incisors against NA line, proclination angle of lower incisors was evaluated choosing outline of the most proclined tooth from the group of all lower incisors against NB line. In order to assess overjet and overbite, measurements of diagnostic models were made.

The outcomes of the diagnostic studies and comparisons of X-ray photographs were subjected to statistical analysis. In order to describe the collected data, descriptive statistics were used, as well as quantities and percentages were calculated. In statistical analysis there was used verification of statistical hypotheses based on the following tests: Pearson's chi-squared test, Student's t-test, Mann-Whitney U test. The Student's t-test was used in comparing 2 independent trials (groups). The Mann-Whitney U test was also used in comparing 2 independent trials (groups) in the case when not all the assumptions for the Student's t-test were fulfilled. The Pearson's chi-squared test was used in studying connection between qualitative data. The study 
results were elaborated with the use of STATISTICA 13.3 software and Microsoft Excel 2016. Significance of differences and dependence was set at $\mathrm{p}<0.05$.

\section{RESULTS}

The conducted study did not prove any significant differences in age in the study and control groups. However, it can be observed that patients from the study group were slightly younger. In the study group the youngest patient was 9 years old, and the oldest one - 37, while in the control group respectively 11 and 43 years old (Tab. 1). No significant connection was found between the group (study and control) and patients' sex, however the result was at the level of statistical tendency (between 0.1 and 0.05 ). Almost every second female patient was assigned to the study group due to EARR occurrence ( $44.6 \%$ out of all female patients), and only every fourth male patient had diagnosed EARR ( $25 \%$ of all the male patients) (Tab. 2 ).

Table 1. Patients' age in the study and control groups

\begin{tabular}{|l|c|c|c|c|c|c|c|c|}
\hline \multirow{2}{*}{ Group } & \multirow{2}{*}{$N$} & \multicolumn{5}{|c|}{ Age } & \multicolumn{2}{|c|}{ Mann-Whitney U test } \\
\cline { 3 - 8 } & & $\underline{x}$ & SD & Min & Max & Me & Z & $p$ \\
\hline Study & 40 & 19.93 & 6.88 & 9.0 & 37.0 & 18.50 & & \\
\hline Control & 61 & 22.23 & 7.44 & 11.0 & 43.0 & 22.0 & -1.62484 & 0.104197 \\
\hline Total & 101 & 21.32 & 7.28 & 9.0 & 43.0 & 21.0 & & \\
\hline
\end{tabular}

Table 2. Patients' sex in the study and control groups

\begin{tabular}{|l|c|c|}
\hline \multirow{2}{*}{ Group } & \multicolumn{2}{|c|}{ Sex } \\
\cline { 2 - 3 } & Female & Male \\
\hline \multirow{3}{*}{ Study } & 34 & 6 \\
\cline { 2 - 3 } & $44.16 \%$ & $25.00 \%$ \\
\hline \multirow{3}{*}{ Control } & 43 & 18 \\
\hline \multirow{3}{*}{ Total } & $55.84 \%$ & $75.00 \%$ \\
\cline { 2 - 3 } & 77 & 24 \\
\cline { 2 - 3 } & $100.0 \%$ & $100.0 \%$ \\
\hline
\end{tabular}

In the studies no significant connection was found between occurrence of apical root resorption and skeletal class diagnosed in patients. In the study group slightly over half of patients was qualified to the class I malocclusions, $1 / 3$ of patients - to the class II, and the remaining patients were diagnosed with prognathism, retrognation or combination of both (class III $=10.00 \%$ ). In the control group, classes I and II malocclusion occurred with similar frequency $(42.62 \% ; 44.26 \%)$, while class III malocclusion was found in $13.11 \%$ of patients (Tab. 3 ).

The study did not show any significant relationship between the group (study and control) the patients belonged and overjet (Tab. 3). In both groups slightly over half of respondents had a correct overjet. In the study group there a little more often occurred a reduced or reverse overjet $(30 \%)$, in the control group - every fourth patient had an increased overjet.

No significant relationship was found between the group (study and control) the patients belonged and overbite.
Table 3. Skeletal class, overjet and overbite in the study and control groups

\begin{tabular}{|c|c|c|}
\hline & \multicolumn{2}{|c|}{ Group } \\
\hline & Study & Control \\
\hline \multicolumn{3}{|c|}{ Skeletal Class } \\
\hline \multirow{2}{*}{ I } & 22 & 26 \\
\hline & $55.00 \%$ & $42.62 \%$ \\
\hline \multirow{2}{*}{ II } & 14 & 27 \\
\hline & $35.00 \%$ & $44.26 \%$ \\
\hline \multirow{2}{*}{ III } & 4 & 8 \\
\hline & $10.00 \%$ & $13.11 \%$ \\
\hline \multirow{2}{*}{ Total } & 40 & 61 \\
\hline & $100.0 \%$ & $100.0 \%$ \\
\hline \multicolumn{3}{|c|}{ Pearson's Chi²: $1.486546 ; p=0.47555$} \\
\hline \multicolumn{3}{|c|}{ Overjet } \\
\hline \multirow{2}{*}{$<2 \mathrm{~mm}$} & 12 & 14 \\
\hline & $30.00 \%$ & $22.95 \%$ \\
\hline \multirow{2}{*}{ Normal } & 23 & 33 \\
\hline & $57.50 \%$ & $54.10 \%$ \\
\hline \multirow{2}{*}{$>4 \mathrm{~mm}$} & 5 & 14 \\
\hline & $12.50 \%$ & $22.95 \%$ \\
\hline \multirow{2}{*}{ Total } & 40 & 61 \\
\hline & $100.0 \%$ & $100.0 \%$ \\
\hline \multicolumn{3}{|c|}{ Pearson's Chi²: $1.919358 ; p=0.38302$} \\
\hline \multicolumn{3}{|c|}{ Overbite } \\
\hline \multirow{2}{*}{ Reduced } & 9 & 12 \\
\hline & $22.50 \%$ & $19.67 \%$ \\
\hline \multirow{2}{*}{$2-4 \mathrm{~mm}$} & 23 & 33 \\
\hline & $57.50 \%$ & $54.10 \%$ \\
\hline \multirow{2}{*}{ Increased } & 8 & 16 \\
\hline & $20.00 \%$ & $26.23 \%$ \\
\hline \multirow{2}{*}{ Total } & 40 & 61 \\
\hline & $100.0 \%$ & $100.0 \%$ \\
\hline \multicolumn{3}{|c|}{ Pearson's Chi²: $0.5378684 ; p=0.76419$} \\
\hline
\end{tabular}

In both groups slightly over half of respondents had a correct overbite, while $22.50 \%$ from the study group and $19.67 \%$ from the control group had a reduced overbite. An increased overbite was observed in $20 \%$ of patients with EARR and in $26.23 \%$ of patients included to the control group (Tab. 3).

Statistical analysis proved a significant relationship between proclination of upper incisors and occurrence of their roots resorption. The persons without extensive root resorption, considerably more frequently had their upper incisors flared correctly (44.26\%), while persons with extensive root resorption considerably more frequently had increased proclination of upper incisors (45\%) (Tab. 4).

Statistical analysis proved a significant relationship between proclination of lower incisors and occurrence of their roots resorption. Persons without extensive root resorption considerably more frequently had their lower incisors proclined below normal, as compared to the study group $(44.26 \% ; 27.50 \%)$, while persons with extensive root resorption considerably more frequently had increased 
proclination of lower incisors, as compared to the control group (32.50\%; 21.31\%) (Tab. 4).

Table 4. Upper and lower incisors proclination in the study and control groups

\begin{tabular}{|c|c|c|c|c|}
\hline & \multicolumn{2}{|c|}{ Upper incisors proclination } & \multicolumn{2}{|c|}{ Lower incisors proclination } \\
\hline & \multicolumn{4}{|c|}{ Group } \\
\hline & Study & Control & Study & Control \\
\hline \multirow{2}{*}{ Below normal } & 40 & 56 & 44 & 108 \\
\hline & $25.00 \%$ & $22.95 \%$ & $27.50 \%$ & $44.26 \%$ \\
\hline \multirow{2}{*}{ Normal } & 48 & 108 & 64 & 84 \\
\hline & $30.00 \%$ & $44.26 \%$ & $40.00 \%$ & $34.43 \%$ \\
\hline \multirow{2}{*}{ Above normal } & 72 & 80 & 52 & 52 \\
\hline & $45.00 \%$ & $32.79 \%$ & $32.50 \%$ & $21.31 \%$ \\
\hline \multirow{3}{*}{ Total } & 160 & 244 & 160 & 244 \\
\hline & $100.0 \%$ & $100.0 \%$ & $100.0 \%$ & $100.0 \%$ \\
\hline & \multicolumn{2}{|c|}{$\begin{array}{c}\text { Pearson's Chi }{ }^{2}: 9.092368 \\
p=0.01061\end{array}$} & \multicolumn{2}{|c|}{$\begin{array}{c}\text { Pearson's Chi }{ }^{2}: 12.73528 \\
p=0.00172\end{array}$} \\
\hline
\end{tabular}

\section{DISCUSSION}

EARR caused by orthodontic treatment is a complex process, specified by mechanic and biological risk factors. Defining EARR risk factors would enable more personalised planning of orthodontic treatment. In the study, an analysis of six factors concerning clinical aspects of treatment was made.

The most precise method of root resorption level evaluation is an analysis of shape and length of the root in the study using the cone beam computed tomography (CBCT) of very high resolution. However, much more available tools for orthodontists are two-dimensional panoramic photos, which are routinely taken before, during or after the treatment, that is why they were used in the above study. Al-Qawasmi et al. for EARR measurement used cephalometric and panoramic photo [17,18]. Dudic et al. claimed that post-orthodontic apical root resorptionis underestimated on 2D orthopanthomograms [3]. CBCT was found to be more accurate than panoramic radiography for detecting root resorption [3,22]. However the radiation dose of CBCT is 2-4 times the effective dose of the panoramic radiograph, which is between 4.7 and $14.9 \mathrm{mSv}$ which is still a matter of debate when choosing the right method of examination [23]. Otherwise Sameshima and Asgarifar suggested that using panoramic photos for root resorption measurement may overestimate an amount of root tissues loss by $20 \%$ or more, and that they are not as precise and reliable as intraoral radiographs [24].

In most of clinical studies, root resorption level was evaluated with two-dimensional measurement methods, such as periapical films, panoramic radiographs and cephalometry. However, EARR has three-dimensional course and may occur in any part of the root. Wang et al. proved that CBCT can precisely measure root resorption bigger than $3.47 \mathrm{~mm}$ [25]. That is why, for further studies CBCT 3D reconstruction should be used to volumetrically measure root resorption.

EARR is a frequent iatrogenic result of orthodontic treatment, especially in maxillary incisors, due to compressed periodontal ligaments. This compression causes reduction or interruption of microcirculation; it may result in sterile necrosis. During the extraction of the necrotic tissue by macrophages, the integrity of roots can be damaged [1]. As it was widely observed in the earlier published studies, the most frequent teeth with resorption were maxillary incisors [26,27]. Also in the present study, resorption the most often concerned maxillary incisors, out of which the most extensive resorption regarded maxillary right lateral incisor. In the studies of other authors, only $5 \%$ of all the tested teeth indicated EARR greater than $20 \%$ root length loss, which is in accordance with the results of the conducted analyses, in which resorptions with the loss greater than $20 \%$ of root length constituted $5.75 \%$ [28]. According to the researchers, only in 5\% of patients extremal resorption occurs, which is often defined as greater than $5 \mathrm{~mm}$ [29]. Pereira et al., in their study, proved that sex was one of the main EARR risk factors [30]. Similarly, Brin et al., Mohandesan et al., Motokawa et al. indicated male sex as a significant predictive factor [31-33]. As opposed to the results obtained by these researchers, in the conducted own study no relationship was found between sex and occurrence of resorption during orthodontic treatment. Despite the lack of statistical significance, almost every second female was included into the study group due to EARR occurrence (44.6\% of all females), and only every fourth male was diagnosed with EARR ( $25 \%$ of all males), which proves more frequent occurrence of resorption among females and does not confirm the results of other researchers, who defined male gender as a significant predictive factor. Only the study by Gue et al., conducted on Chinese population with independent Student's t-test, proved that an average volume of root resorption in women was greater than in men, however the difference was not significant [34].

In the conducted study, no significant differences concerning age in the study and control groups were found. Patients from the study group were slightly younger. In the study group the youngest patient was 9 , and the oldest one -37 , while in the control group respectively 11 and 43 . Some researchers also did not prove any influence of age on root resorption [35-37]. Only Sameshima and Sinclair observed that resorption is more common in adults than in children [38]. Adults seem to be more susceptible to resorption, as together with aging, the periodontal tissues become less vascularized, inflexible, thinner, and the apical third of the root in adults is more closely anchored, causing difficulties in teeth movement and predisposing to resorption $[9,39]$. However, the results of these researchers' studies need to be interpreted carefully, as age difference between the study and control groups was only approximately three years.

Various studies prove that there is no relationship between root resorption and type of malocclusion [35,37,39,40]. In the study conducted by Harris et al., skeletal class was evaluated on the basis of ANB angle and Wits appraisal (AOBO). The authors observed a strong relationship with resorption occurrence, as greater $\mathrm{AOBO}$ discrepancies tend to require greater retraction of the anterior teeth, therefore increase the risk of resorption [37]. In the own study no relationship was found between the type of skeletal malocclusion and EARR occurrence. 
The results of the study by Picanço et al. did not prove any statistically significant differences between the control and the study group when it comes to overjet and overbite, which indicated that there is the same probability of EARR occurrence in patients with correct, increased or reduced overjet and overbite. The analysis of Picanço et al. suggested that at the beginning of treatment these variables are not risk factors for occurrence of extensive root resorption [41]. The own studies also did not prove any significant differences between the values of overjet and overbite, and resorption occurrence during the orthodontic treatment. The results obtained in Picanço's and own studies were, however, contrary to those of other authors and could be explained by lack of great skeletal discrepancies, as well as with lack of significant number of cases with open bite and/or deep bite [41].

In the study by Chiqueto et al. a statistically significant correlation of root resorption with initial deep bite and level of its correction was found [42]. This correlation was in accordance with some other studies in the literature, indicating that the intrusion can be considered a factor predisposing to resorption, in the cases with extraction [8,32] and without it [42]. Guangli Han et al. concluded that intrusive force of $100 \mathrm{cN}$ induces nearly four times more severe root resorption than of extrusion using the same force [43]. Furthermore, greater resorption level and greater proportion of resorpted teeth are expected when the intrusion mechanics is connected with extraction and retraction mechanics [44]. For this reason, intrusion mechanisms should be carefully used, especially in patients, who require significant reverse movements. In the studies by Martins et al. the patients with increased overbite treated with intrusion mechanics in order to accentuate and reverse curve of Spee, in combination with anterior teeth retraction, had statistically greater maxillary incisors root resorption than patients with correct overbite, not requiring intrusion [44]. On the other hand no correlation was found between the amount of en-masse retraction, intrusion, or palatal tipping of maxillary incisors and EARR in patients treated using miniscrews [45].

According to canonical Steiner's analysis presented over 60 years ago, the correct angle of upper incisors proclination should be equal to $22 \pm 4^{\circ}$, and of lower incisors $25 \pm 4^{\circ}$ [46]. In the conducted study, a significant dependence between the starting inclination angle of maxillary and mandibular incisors and EARR occurrence was observed. Persons with extensive root resorption significantly more often had an increased proclination angle of maxillary and mandibular incisors in relation to the control group, respectively: $45.00 \% ; 32.79 \%$ and $32.50 \% ; 21.31 \%$. The increased proclination of incisors, both upper and lower ones, can be a risk factor for occurrence of apical root resorption during orthodontic treatment. Patients with incisors proclination showed greater susceptibility to resorption probably because mechanical anterior teeth retraction causes bigger movement of root apex, often requires extraction or distalization, which influences treatment prolongation. The results obtained in the own studies are varying from the results of Picanço et al., who did not find any statistically significant difference between the groups depending on the starting position of incisors [41].
To sum up, it needs to be stated that an increased proclination angle of incisors is a factor predisposing to occurrence of postorthodontic EARR. However, in the case of multifactorial diseases, such as EARR, it is typical that each of the individual and orthodontic factors generally has slight impact, and interactions between them influence the observed clinical phenotype. Due to small number of participants included into the own study, number of conducted comparisons, and only insubstantial significant differences found, the presented results need to be interpreted with caution. Further clinical observations should concern more numerous population.

\section{CONCLUSIONS}

1. Age, sex and type of skeletal malocclusion do not constitute risk factors for occurrence of external apical root resorption during the orthodontic treatment with fixed braces.

2. Increased overjet and overbite do not pose a risk for EARR occurrence.

3. Maxillary and mandibular incisors proclination predisposes to shortening of the incisors roots during the orthodontic treatment.

\section{CONFLICTS OF INTEREST}

The authors declare that there are no conflicts of interest.

\section{ORCID iDs}

Jolanta Szymańska (Dhttps://orcid.org/0000-0002-9917-2907 Agata Ciurla (Dhttps://orcid.org/0000-0001-9038-2871

\section{REFERNCES}

1. Brezniak N, Wasserstein A. Orthodontically induced inflammatory root resorption. Part I: The basic science aspects. Angle Orthod. 2002;72:175-9.

2. Brezniak N, Wasserstein A. Orthodontically induced inflammatory root resorption. Part II: The clinical aspects. Angle Orthod. 2002; 72(2):180-4.

3. Dudic A, Giannopoulou C, Leuzinger M, Kiliaridis S. Detection of apical root resorption after orthodontic treatment by using panoramic radiography and cone-beam computed tomography of super-high resolution. Am J Orthod Dentofacial Orthop. 2009;135(4): 434-7.

4. Leach H, Ireland A, Whaites E. Radiographic diagnosis of root resorption in relation to orthodontics. Br Dent J. 2001;190:16-22 .

5. Rudolph CE. A comparative study in root resorption in permanent teeth. J Am Dent Assoc. 1936;23:822-6.

6. Harris EF, Robinson QC, Woods MA. An analysis of causes of apical root resorption in patients not treated orthodontically. Quintessence Int. 1993;24:417-28.

7. Harris EF, Butler ML. Patterns of incisor root resorption before and after orthodontic correction in cases with anterior open bites. Am J Orthod Dentofacial Orthop. 1992;101(2):112-9.

8. Brezniak N, Wasserstein A. Root resorption after orthodontic treatment. Part 2. Literature review. Am J Orthod Dentofac. 1993; 103(1):62-6.

9. Feller L, Khammissa R, Thomadakis G, Fourie J, Lemmer J. Apical external root resorption and repair in orthodontic tooth. Movement: Biological Events. 2016;2:1-7.

10. Weltman B, Vig KWL, Fields HW, Shanker S, Kaizer EE. Root resorption associated with orthodontic tooth movement: A systematic review. Am J Orthod Dentofacial Orthop. 2010;137:462-76. 
11. Rauka R, Gulve N, Nehete A, Shah K,Aher S. Root resorption associated with orthodontic tooth movement. J Dent Med Sci. 2018;17:23-6.

12. Apajalahti S, Peltola JS. Apical root resorption after orthodontic treatment - a retrospective study. Eur J Orthod. 2007;29:408-12.

13. Marques LS, Ramos-Jorge ML, Rey AC, Armond MC, Ruellas AC. Severe root resorption in orthodontic patients treated with the edgewise method: prevalence and predictive factors. Am J Orthod Dentofacial Orthop. 2010;137(3):384-8.

14. Linhartova P, Cernochova P, Izakovicova Holla L. IL1 gene polymorphisms in relation to external apical root resorption concurrent with orthodontia. Oral Dis. 2013;19:262-70.

15. Sharab LY, Morford LA, Dempsey J, Falcão-Alencar G, Mason A Jacobson E, et al. Genetic and treatment-related risk factors associated with external apical root resorption (EARR) concurrent with orthodontia. Orthod Craniofac Res. 2015;18(Suppl. S1):71-82.

16. Linhartova PB, Cernochova P, Kastovsky J, Vrankova Z, Sirotkova M, Izakovicova Holla L. Genetic determinants and postorthodontic external apical root resorption in Czech children. Oral Dis. 2017;23: 29-35.

17. Al-Qawasmi RA, Hartsfield Jr JK, Everett ET, Flury L, Liu L, Foroug TM, et al. Genetic predisposition to external apical root resorption. Am J Orthod Dentofacial Orthop. 2003;123:242-52.

18. Al-Qawasmi RA, Hartsfield Jr JK, Everett ET, Flury L, Liu L, Foroug TM, et al. Genetic predisposition to external apical root resorption in orthodontic patients: linkage of chromosome-18 marker. J Dent Res. 2003;82: 356-60.

19. Linge L, Linge BO. Patient characteristics and treatment variables associated with apical root resorption during orthodontic treatment. Am J Orthod Dentofacial Orthop. 1991;99:35-43.

20. Brezniak N, Goren S, Zoizner R, Dinbar A, Arad A, Wasserstein A et al. A comparison of three methods to accurately measure root length. Angle Orthod. 2004;74: 786-91.

21. Houston WJ. The analysis of error in orthodontic measurements. Am J Orthod. 1983;83:382-90.

22. Alqerban A, Jacobs R, Fieuws S, Willems G. Comparison of two cone beam computed tomographic systems versus panoramic imaging for localization of impacted maxillary canines and detection of root resorption. Eur J Orthod. 2011;33(1):93-102.

23. Gijbels F, Jacobs R, Debaveye D, Bogaerts R, Verlinden S, Sanderink G. Dosimetry of digital panoramic imaging. Part II: occupational exposure. Dentomaxillofac Rad. 2005;34:150-3.

24. Sameshima GT, Asgarifar KO. Assessment of root resorption and root shape: periapical vs panoramic films. Angle Orthod. 2001;71: $185-9$.

25. Wang Y, He S, Guo Y, Wang S, Chen S. Accuracy of volumetric measurement of simulated root resorption lacunas based on cone beam computed tomography. Orthod Craniofac Res. 2013;16:169-76.

26. Smale I, Artun J, Behbehani F, Doppel D, van't Hof M, KuijpersJagtman AM. Apical root resorption 6 months after initiation of fixed orthodontic appliance therapy. Am J Orthod Dentofacial Orthop. 2005;128:57-67.

27. Kocadereli I, Yesil TN, Veske PS, Uysal S. Apical root resorption: a prospective radiographic study of maxillary incisors. Eur J Dent. 2011;5:318-23.

28. Maues CP, do Nascimento RR, Vilella Ode V. Severe root resorption resulting from orthodontic treatment: prevalence and risk factors. Dental Press J Orthod. 2015;20:52-8.
29. Hartsfield JK, Everett ET, Al-Qawasmi RA. Genetic factors in external apical root resorption and orthodontic treatment. Crit Rev in Oral Biol Med. 2004;15:115-22.

30. Pereira S, Lavado N, Nogueira L, Lopez M, Abreu J, Silva H. Polymorphisms of genes encoding P2X7R, IL1B, OPG a RANK in orthodontic-induced apical root resorption. Oral Dis. 2014;20:659-67.

31. Brin I, Tulloch JFC, Koroluk L, Philips C. External apical root resorption in class II malocclusion: a retrospective review of 1- versus 2-phase treatment. Am J Orthod Dentofacial Orthop. 2003;124:151-6.

32. Mohandesan $\mathrm{H}$, Ravanmehr $\mathrm{H}$, Valaei N. A radiographic analysis of external apical root resorption of maxillary incisors during active orthodontic treatment. Eur J Orthod. 2007;29:134-9.

33. Motokawa M, Sasamoto T, Kaku M, Kawata T, Matsuda Y, Terao A, et al. Association between root resorption incident to orthodontic treatment and treatment factors. Eur J Orthod. 2012;34:350-6.

34. Guo Y, He S, Gu T, Liu Y, Chen S. Genetic and clinical risk factors of root resorption associated with orthodontic treatment. Am J Orthod Dentofacial Orthop. 2016;150(2):283-9.

35. Barroso MCF, Devita RL, Lages EJP, Costa FO, Drummond AF, Pretti $\mathrm{H}$, et al. Risk variables of external apical root resorption during orthodontic treatment. Dental Press J Orthod. 2012;17(2): 39.e1-39.e7.

36. Consolaro A. Reabsorções dentárias nas especialidades clínicas. $2 \mathrm{a}$ ed. Maringá: Dental Press. 2005:p.616.

37. Harris EF, Kineret SE, Tolley EA. A heritable component for external apical root resorption in patients treated orthodontically. Am J Orthod Dentofacial Orthop. 1997;111(3):301-9.

38. Sameshima GT, Sinclair PM. Predicting and preventing root resorption: Part I. Diagnostic factors. Am J Orthod Dentofac Orthop. 2001;119:505-10.

39. Capelozza Filho L, Silva Filho OG. Reabsorção radicular na clínica ortodôntica: atitudes para uma conduta preventiva. Rev Dental Press Ortod Ortop Facial. 1998;3(1):104-26.

40. Mirabella AD, Artun J. Risk factors for apical root resorption of maxillary anterior teeth in adult orthodontic patients. Am J Orthod Dentofacial Orthop. 1995;108(1):48-55.

41. Picanço GV, Freitas KMS, Cancado RH, Valarelli FP, Picanço PRB, Feijão CP. Predisposing factors to severe external root resorption associated to orthodontic treatment. Dental Press J Orthod. 2013; 18:110-20.

42. Chiqueto K, Martins DR, Janson G. Efects of accentuated and reversed curve of Spee on apical root resorption. Am J Orthod Dentofacial Orthop. 2008;133(2):261-8.

43. Han G, Huang S, Von den Hoff J, Zeng X, Kuijpers-Jagtman AM. Root resorption after orthodontic intrusion and extrusion: An intraindividual study. Angle Orthod. 2005;75:912-8.

44. Martins DR, Tibola D, Janson G, Maria FR. Effects of intrusion combined with anterior retraction on apical root resorption. Eur J Orthod. 2012;34:170-5.

45. Liou E,Chang P. Apical root resorption in orthodontic patients with en-masse maxillary anterior retraction and intrusion with miniscrews. J Orthod Dentofacial Orthop. 2010;137(2):207-12.

46. Steiner CC. Cephalometrics in clinical practice. Angle Orthod. 1959;29:8-29. 